\title{
Role of magnetic resonance imaging versus ultrasound for detection of plantar plate tear
}

\author{
Xin Duan ${ }^{1 \dagger}$, Lang $\mathrm{Li}^{1 \dagger}$, Dai-Qing Wei ${ }^{2}$, Ming Liu' ${ }^{1}, \mathrm{Xi} \mathrm{Yu}^{1}$, Zhao Xu${ }^{3}$, Ye Long ${ }^{1}$ and Zhou Xiang ${ }^{1 *}$
}

\begin{abstract}
Background: Plantar plate tears could be the reason of forefoot pain, affecting foot function. Magnetic resonance imaging (MRI) and ultrasound (US) were commonly used for the diagnosis of plantar plate tears. The decision of whether to use MRI or US carried some controversy. Our study aimed to find out the diagnostic accuracy of MRI versus US for plantar plate tears.

Methods: The database of the Cochrane Central Register of Controlled Trials (CENTRAL), PubMed, EMBASE, and relative orthopedic meetings until May 2016 were searched. Studies involved in the diagnostic detection of MRI or ultrasound for plantar plate tears with surgical criteria as the reference test were included. Data was analyzed by meta-analysis. We compared sensitivity, specificity, positive likelihood ratio, negative likelihood ratio, and summary receiver operating characteristic (SROC) plot of both MRI and US.
\end{abstract}

Results: Seven studies involving 246 plantar plate tears were included. The MRI showed more diagnostic accuracy than US for the detection of plantar plate tears. The sensitivity, specificity, positive likelihood ratio, and negative likelihood ratio of MRI were $95 \%, 54 \%, 2.08$, and 0.08 , respectively, while the same values for US were 93\%, 33\%, 1.20 , and 0.35 , respectively. And the sROC showed more superior diagnostic accuracy than the US.

Conclusion: The current result suggests that MRI has better accuracy than US for detection of plantar plate tears.

Keywords: MRI, Ultrasonic sound, Plantar plate tear, Diagnosis

\section{Background}

Plantar plates which are made of fibrocartilaginous structures were found in the metatarsophalangeal (MTP) joints. The average length, width, and thickness of plantar plates are 16,9 , and $1.8 \mathrm{~mm}$, respectively $[1,2]$. It is located in the central of plantar aspect of the lesser MTP, with the function of supporting the body weight and restricting dorsiflexion [3]. The plantar plate attached to the major longitudinal bands of the plantar fascia, proximal phalanx, and collateral ligaments play an active role in the ankle [1]. Plantar plate tears can be the reason of forefoot pain, affecting foot function and gait $[4,5]$. Instability of the MTP joint caused by plantar plate

\footnotetext{
* Correspondence: xiangzhou15@hotmail.com

${ }^{\dagger}$ Equal contributors

${ }^{1}$ Orthopedics Department, West China Hospital, Sichuan University, \#37

Guoxuexiang Street, Chengdu 610017, Sichuan Province, China

Full list of author information is available at the end of the article
}

tears has been widely reported and has frequently occurred in uncomfortable footwear [6-8].

The diagnosis of instability is based on clinics but could be improved by imaging studies [2]. Magnetic resonance imaging (MRI) and ultrasound (US) have been commonly used to detect plantar plate tear previously. MRI is a noninvasive method compared to arthrography for the detection of plantar plate and helped to identify intra-articular and extraarticular diagnoses [3, 7]. MRI is frequently used to assess this structure. However, MRI is expensive machine and not every hospital has the MRI. Meanwhile, MRI could not be used in some conditions, such as implant of cardiac pacemakers or automatic defibrillators. US is an available way to assess some disease by pulsed ultrasonic waves. The use of diagnostic ultrasound in the identification of plantar plate tears has been increasingly reported $[9,10]$. 
Table 1 Search strategy

\begin{tabular}{|c|c|c|}
\hline CENTRAL & PubMed & EMBASE \\
\hline $\begin{array}{l}\text { \#1 MeSH descriptor plantar plate, this term only \#2 } \\
\left({ }^{*} \text { planta*) :ti,ab,kw \#3 (\#1 OR \#2) \#4 MeSH descriptor }\right. \\
\text { MRI, this term only \#5 MeSH descriptor magnetic } \\
\text { resonance imaging, \#6 MeSH descriptor US, this term } \\
\text { only \#7 MeSH descriptor ultrasonography \#8 } \\
\text { (\#4 OR \#5 OR \#6 OR \#7) \#9 (\#3 AND \#8) }\end{array}$ & $\begin{array}{l}\text { (plantar[All Fields] AND ("bone plates"[MeSH Terms] OR } \\
\text { ("bone"[All Fields] AND "plates"[All Fields]) OR "bone plates" } \\
\text { [All Fields] OR "plate"[All Fields]) AND ("magnetic resonance } \\
\text { imaging"[MeSH Terms] OR ("magnetic"[All Fields] AND } \\
\text { "resonance"[All Fields] AND "imaging"[All Fields]) OR } \\
\text { "magnetic resonance imaging"[All Fields] OR "mri"[All Fields])) } \\
\text { OR (plantar[All Fields] AND ("bone plates"[MeSH Terms] OR } \\
\text { ("bone"[All Fields] AND "plates"[All Fields]) OR "bone plates" } \\
\text { [All Fields] OR "plate"[All Fields]) AND } \\
\text { ("ultrasonography"[Subheading] OR "ultrasonography" } \\
\text { [All Fields] OR "ultrasound"[All Fields] OR "ultrasonography" } \\
\text { [MeSH Terms] OR "ultrasound"[All Fields] OR "ultrasonics" } \\
\text { [MeSH Terms] OR "ultrasonics"[All Fields])) }\end{array}$ & $\begin{array}{l}\text { 1. 'Plantar'/exp OR Plantar } \\
\text { 2. 'magnetic resonance } \\
\text { imaging'/exp OR 'magnetic } \\
\text { resonance imaging' } \\
\text { 3. 'MRI'/exp OR 'MRI' } \\
\text { 4. 'ultrasonography'/exp OR } \\
\text { ultrasonography } \\
\text { 5. 'ultrasonics'/exp OR } \\
\text { ultrasonics } \\
\text { 6. 'US'/exp OR 'US' } \\
\text { 7. \#2 OR \#3 } \\
\text { 8. \#4 OR \#5 OR \#6 } \\
\text { 9. \#1 AND \#7 AND \#8 }\end{array}$ \\
\hline
\end{tabular}

Diagnostic ultrasound is easy to use and provide a relatively inexpensive option compared with other advanced imaging modalities. However, the US needed skillful operator lead to its limitation [11]. Therefore, the decision of whether to use MRI or US carried some controversy. This study aims to determine the diagnostic accuracy test of MRI versus US for plantar plate tears.

\section{Review}

\section{Search strategy}

This study adhered to the Preferred Reporting Items for Systematic Reviews and Meta-Analyses (PRISMA) guidelines [12]. Any original study, published in a peer reviewed journal, which accessed the diagnostic test accuracy (sensitivity, specificity, positive likelihood ratio, and negative likelihood ratio) of MRI or ultrasound for the detection of adults ( $>18$ years old) with suspect plantar plate tears was included. Surgery or arthroscopy as reference test was included. Studies assessing cadaveric, animal models, pediatric patients, or without diagnostic test accuracy were excluded.
An online searching was conducted for this studies and no language limitation. The Cochrane Central Register of Controlled Trials (CENTRAL), PubMed, EMBASE (to May 2016), and relative orthopedic meetings were searched. The search strategy is shown in Table 1 . For the studies reported in duplicate, only the latest or complete reports were collected.

\section{Methodological quality assessment}

Data were selected by two independent authors. The premier inclusion of studies was based on titles, abstracts, and keywords. Studies were included in the end when all authors agreed. Any differences or contradictions were resolved by discussion. The study quality was assessed by one author and independently verified by another author using the QUADAS form [13, 14] and following the guidelines provided in the Cochrane Handbook [15].

\section{Review process and statistical analysis}

After included studies were collected, the software of the software Meta-DiSc version 1.4 (Unit of Clinical Biostatistics, Ramóny Cajal Hospital, Madrid, Spain.) and

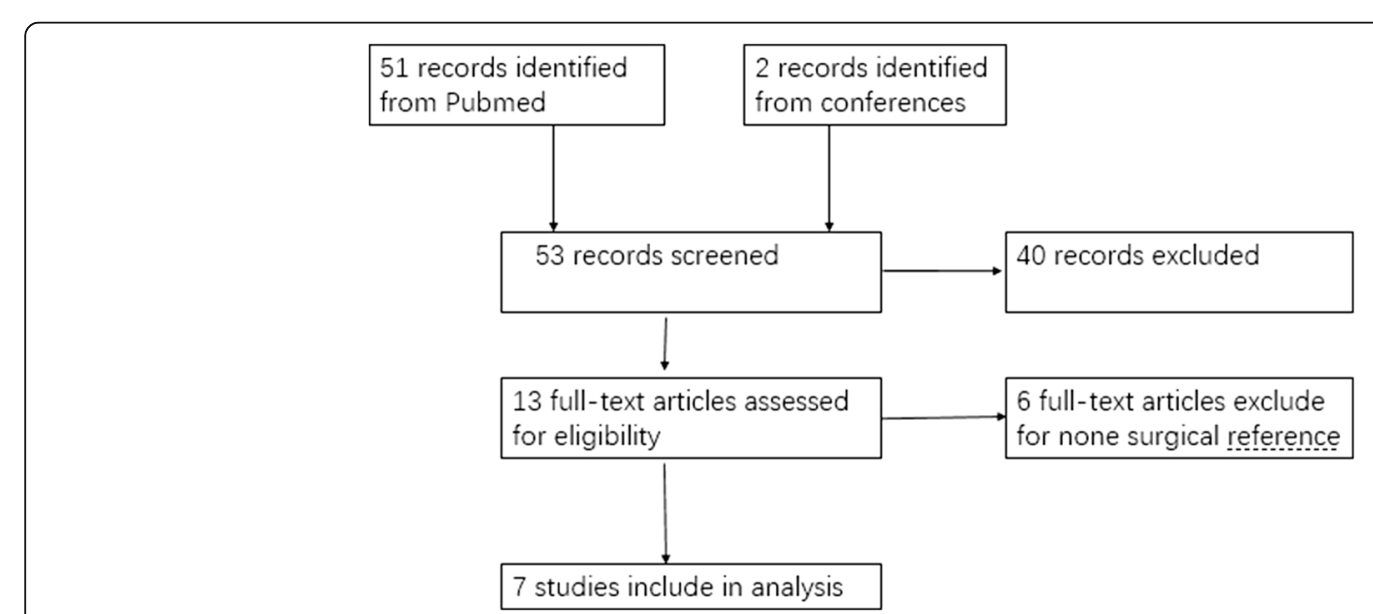

Fig. 1 The flow chart shows how the articles were selected for eligible study 
Table 2 Characteristics of included studies

\begin{tabular}{|c|c|c|c|c|c|c|c|}
\hline \multirow[t]{2}{*}{ Studies } & \multirow{2}{*}{$\begin{array}{l}\text { Number of } \\
\text { samples }\end{array}$} & \multirow{2}{*}{ Index text } & \multirow[t]{2}{*}{ Age } & \multicolumn{2}{|c|}{ Gender } & \multirow[t]{2}{*}{ Parameter of index text } & \multirow{2}{*}{$\begin{array}{l}\text { Reference } \\
\text { standard }\end{array}$} \\
\hline & & & & Male & Female & & \\
\hline $\begin{array}{l}\text { Carlson et al. } 2013 \\
\text { [16] }\end{array}$ & 8 & US & $51.9(41-63)$ & 0 & 8 & Acuson Sequoia 512 Ultrasound Scanner (Siemens) & Surgery \\
\hline $\begin{array}{l}\text { Gregg et al. } 2006 \\
{[11]}\end{array}$ & 50 & $\begin{array}{l}\text { MRI and } \\
\text { US }\end{array}$ & $57(18-74)$ & N/A & N/A & $\begin{array}{l}\text { MRI: 1.5-T MRI scanner (Signa Hi Speed Plus, } \\
\text { General Electric Medical Systems) } \\
\text { US: Antares scanner, (Siemens)with a high-frequency } \\
\text { linear array probe (13-5VF; } 11.4 \mathrm{MHz} \text {; dynamic } \\
\text { range } 60 \mathrm{~dB} \text {; one focal zone) }\end{array}$ & Surgery \\
\hline Klein et al. 2012 [10] & 52 & MRI & N/A & N/A & N/A & 0.3 T extremity coil & Surgery \\
\hline Klein et al. 2013 [17] & 50 & US & N/A & N/A & N/A & $\begin{array}{l}\text { Sonosite M-turbo ultrasound and a linear } 15-6 \mathrm{MHz} \\
\text { transducer }\end{array}$ & Surgery \\
\hline Nery et al. 2013 [18] & 36 & MRI & $61(43-75)$ & 8 & 20 & 1.0 to $1.5 \mathrm{~T}$ & Arthroscopy \\
\hline Sung et al. 2012 [19] & 45 & MRI & $52.1(28-70)$ & 3 & 38 & $\begin{array}{l}0.31 \mathrm{~T} \text { (O-Scan Extremity MRI, Biosound Esaote, } \\
\text { Indianapolis, IN) }\end{array}$ & Surgery \\
\hline Yao et al. 1996 [20] & 5 & MRI & N/A & N/A & N/A & 1.5 T (General Electric, Signa, Milwaukee, WI) & Surgery \\
\hline
\end{tabular}

Review Manager 5.2 (The Nordic Cochrane Centre, The Cochrane Collaboration, 2012) was used for the statistical analysis. The analysis assessed sensitivity, specificity, positive likelihood ratios, and negative likelihood ratios for both MRI and US. For each analysis, 95\% confidence intervals $(\mathrm{CI})$ were adopted. Heterogeneity was tested by chi-square and Cochran-Q test. A $P$ value of less than 0.05 was considered statistically significant. The fixedeffect model (Mantel-Haenszel test) and 95\% CI were used initially. The random-effects model (DerSimonianLaird test) was also considered to be used in which there was heterogeneity. Finally, summary receiver operating characteristic (sROC) plot was arranged to accesses the superior diagnostic accuracy for MRI and US.

\section{Result}

The search flow is shown in Fig. 1. A total of 53 papers were retrieved from the search strategy. After a review of the abstract and full texts, seven trials matched the inclusion criteria [10, 11, 16-20]. Two reported US for plantar plate tear $[16,17]$, four reported MRI for plantar plate tear [10, 18-20], and one [11] reported both US and MRI for plantar plate tear. All seven included studies were published in journals. A total of 246 samples were included (83 for US and 163 for MRI). The key characteristics of included studies are shown in Table 2.

The results for QUADAS methodological appraisal tool are shown in Table 3 . The most primary limitation was uninterpretable/intermediate test results. It was unclear in all studies whether uninterpretable, indeterminate, or intermediate result was reported or not. The second frequent limit was the failure caused by the time period between index test and reference standard. When controlled, this removed the potential of a change in clinical status between investigations. The inclusion criteria were described in the methods of study, and the terms of inclusion were appropriately given to the nature of the pathology. Similarly, the inclusion criteria were also clearly documented between the individual studies. One study using MRI and one study using US which presented their imaging protocols insufficiently was not to allow its replication. The specific details of the surgical criteria were not clear among two studies.

Five studies, based on 163 samples, assessed the diagnostic test accuracy of MRI on tear of the plantar

Table 3 QUADAS appraisal tool results

\begin{tabular}{lllllllllllllll}
\hline study & 1 & 2 & 3 & 4 & 5 & 6 & 7 & 8 & 9 & 10 & 11 & 12 & 13 & 14 \\
\hline Carlson 2013 [16] & $Y$ & $N$ & $Y$ & $U$ & $Y$ & $Y$ & $Y$ & $N$ & $Y$ & $Y$ & $Y$ & $Y$ & $U$ & $N / A$ \\
Gregg 2006 [11] & $Y$ & $Y$ & $Y$ & $U$ & $Y$ & $Y$ & $Y$ & $Y$ & $Y$ & $Y$ & $Y$ & $Y$ & $N$ & N/A \\
Klein 2012 [10] & $Y$ & $Y$ & $Y$ & $U$ & $Y$ & $Y$ & $Y$ & $Y$ & $Y$ & $Y$ & $Y$ & $Y$ & $N$ & N/A \\
Klein 2013 [17] & $Y$ & $Y$ & $Y$ & $U$ & $Y$ & $Y$ & $Y$ & $Y$ & $Y$ & $Y$ & $Y$ & $Y$ & $N$ & N/A \\
Nery 2013 [18] & $Y$ & $Y$ & $Y$ & $U$ & $Y$ & $Y$ & $Y$ & $Y$ & $Y$ & $Y$ & $Y$ & $Y$ & $N$ & N/A \\
Sung 2012 [19] & $Y$ & $Y$ & $Y$ & $U$ & $Y$ & $Y$ & $Y$ & $N$ & $Y$ & $Y$ & $Y$ & $Y$ & $N$ & N/A \\
Yao 1996 [20] & $Y$ & $Y$ & $N$ & $U$ & $N$ & $Y$ & $N$ & $N$ & $Y$ & $Y$ & $Y$ & $Y$ & $N$ & N/A
\end{tabular}

(1) Was the spectrum of patient representative of the patients who will receive the test in practice? (2) Were selection criteria clearly described? (3) Is the reference standard likely to correctly classify the target condition? (4) Is the time period between reference standard and index test short enough to be reasonably sure that the target condition did not change between the two tests? (5) Did the whole sample or a random selection of the sample receive verification using a reference standard of diagnosis? (6) Did patients receive the same reference standard regardless of the index test result? (7) Was the reference standard independent of the index test (i.e., the index test did not form part of the reference standard)? (8) Was the execution of the index test described in sufficient detail to permit replication of the test? (9) Was the execution of the reference standard described in sufficient detail to permit its replication? (10) Were the index test results interpreted without knowledge of the results of the reference standard? (11) Were the reference standard results interpreted without knowledge of the results of the index test? (12) Were the same clinical data available when test results were interpreted as would be available when the test is used in practice? (13) Were uninterpretable/intermediate test results reported? (14) Were withdrawals from the study explained? 


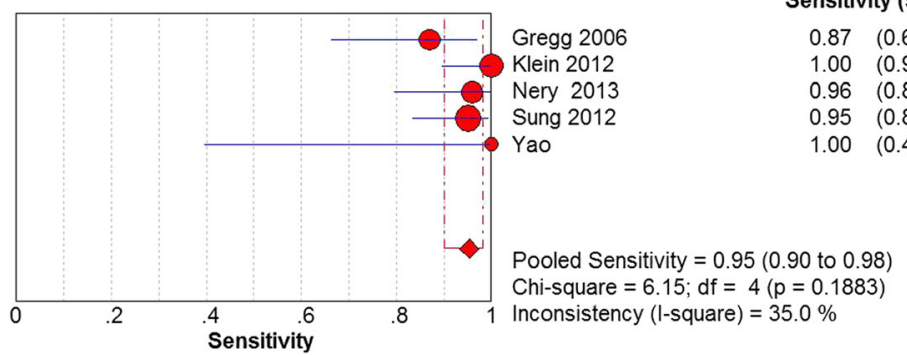

Sensitivity $(95 \% \mathrm{Cl})$

$0.87 \quad(0.66-0.97)$

$100 \quad(0.90-1.00)$

$96 \quad(0.80-1.00)$

$0.95 \quad(0.83-0.99)$

$(0.40-1.00)$

Fig. 2 Forest plot depicting the sensitivity for the use of MRI in the detection of plantar plate tears

plate. The estimates for the sensitivity of MRI were 95\% (95\% CI 90 to 98\%). No significant heterogeneity was detected among five studies $\left(\mathrm{Chi}^{2}=6.15\right.$, degrees of freedom $(d f)=4, I^{2}=35.0 \%, P=.1883$ ) (Fig. 2). The specificity of MRI was analyzed for 54\% (95\% CI 37 to $71 \%$ ), random effects model was used because of the existence of substantial heterogeneity $\left(\mathrm{Chi}^{2}=\right.$ 17.23, $d f=4, I^{2}=76.8 \%, P=.00017$ ) (Fig. 3). The positive LR of MRI was estimated to be 2.08 (95\% CI 0.91 to 4.73 ). The heterogeneity test indicated a statistical evidence of heterogeneity and we pooled data by a random effects model $\left(\mathrm{Chi}^{2}=17.00, \mathrm{~d} f=4, I^{2}=\right.$ $76.5 \%, P=.0019$ ) (Fig. 4). The test of the negative LR of MRI showed 0.08 (95\% CI 0.04-0.20). No significant heterogeneity was detected among five studies $\left(\mathrm{Chi}^{2}=3.48, d f=4, I^{2}=0.0 \%, P=.4644\right)$ (Fig. 5).

Three studies including 83 patients with US assessed the diagnostic accuracy of plantar plate tear. The sensitivity of US was found to be $93 \%$ (95\% CI 84 to $98 \%$ ). Heterogeneity did not exist among three studies $\left(\mathrm{Chi}^{2}=\right.$ $0.95, d f=2, I^{2}<0.01, P=.6223$ ) (Fig. 6). It was estimated that the specificity of US was 33\% (95\% CI 10 to 65\%). No significant heterogeneity was detected among three studies $\left(\mathrm{Chi}^{2}=3.54, d f=2, I^{2}=43.5 \%, P=.1701\right)$ (Fig. 7). The positive LR of US was revealed as 1.20 (95\% CI 0.87 to 1.66 ). No statistically significant heterogeneity was observed among three studies. $\left(\mathrm{Chi}^{2}=1.40, d f=2\right.$, $I^{2}=0.0 \%, P=.4975$ ) (Fig. 8). The summary estimates for the negative LR of US was 0.35 (95\% CI 0.09 to 1.43 ).
No statistical heterogeneity was presented among three studies $\left(\mathrm{Chi}^{2}=0.21, d f=2, I^{2}=0.0 \%, P=.9002\right)$ (Fig. 9).

As demonstrated in sROC, a better diagnostic accuracy for MRI was showed compared with US for the plantar plate tear diagnosis (Fig. 10).

\section{Discussion}

The purpose of this study was to provide a better choice for detection of plantar plate tear. A similar rate was shown on sensitivities of MRI (95\%) and US (93\%) for assessment of plantar plate tear. US (33\%) had lower specificity than MRI (55\%) for plantar plate tears. Compared to US, MRI showed a higher positive LR (2.12 VS $1.20)$ and lower negative LR (0.08 VS 0.35). Based on the findings of this study, the results indicated that the MRI was superior to US for the detection of plantar plate tears in foot. It could also be concluded that MRI was superior to US on pathology.

The results of the QUADAS evaluation tool supported the suggestion that the current evidence-based study presented with a number of methodological limitations. One of the major limitations was uninterpretable test results. These problems were not often reported on studies for the accuracy of plantar plate tears, and the uninterpretable results were simply removed from studies. This may lead to bias of result for the test characteristics [13]. Besides, the studies poorly documented the duration between the reference and index tests. This is an important variable as

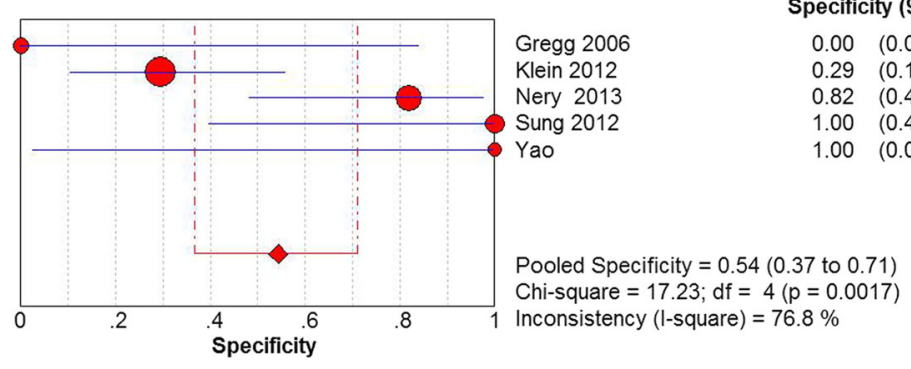

Fig. 3 Forest plot depicting the specificity for the use of MRI in the detection of plantar plate tears 


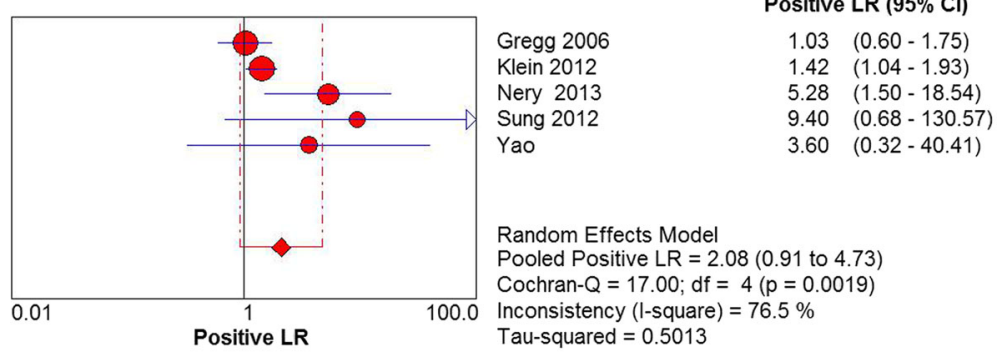

Fig. 4 Forest plot depicting the positive likelihood ratio (PLR) for the use of MRI in the detection of plantar plate tears

pathology may be changing during the time elapsed between the reference and index tests. If there was a delay between reference and index tests, disease progression bias existed as misclassification. Each of these limitations should be considered in the future.

MRI was the most common method for detecting plantar plate. Yao firstly reported that MRI was thought to be better chosen compared to arthrography for assessment of plantar plate tears as a small local coil was used [11, 21]. MRI has been found both to be highly sensitive and to have specific modality for detecting of the plantar plate. In Sung's study, MRI was found to have $96 \%$ accuracy, with $95 \%$ sensitivity, and $100 \%$ specificity [19]. In Klein's study, MRI was found to be with $73.9 \%$ sensitivity and $100 \%$ specificity [10]. In our study, the sensitivity and specificity are 95 and $54 \%$.

The use of diagnostic ultrasound in the identification of plantar plate tears has been increasingly reported [ 9 , $10,16,17]$. Ultrasound is an efficient choice to detect the presence of pathology of the plantar plate. In Klein's study [17], ultrasound was found to be with $91.1 \%$ sensitivity and $25 \%$ specificity. However, a study showed that the positive rate of MTP drawer test in grade 1 MTP instability was found in $34.4 \%$ of joints with normal US finding [22]. In our study, the sensitivity and specificity of US are 93 and $33 \%$.

Whether US can replace MRI for plantar plate tears was still debated. In Gregg's standpoint [11], US is a dynamic examination that is inexpensive and safe, and is a viable alternative to MRI. Nonetheless, on Klein's point [10], MRI is better able to detect plantar plate tear and localize pathology. The US is a less time consuming, and more comfortable detection, but US could not substitute MRI in all conditions. Based on our results, MRI was supported for the test of plantar plate tears because of MRI with lower negative LR, higher specificity, and positive LR and the same sensitivity than US.

The results of this diagnostic test accuracy study suggested that MRI was superior to US for detecting the plantar plate tears. However, the results of this study must also be interpreted attentively as the analyses demonstrated high $I^{2}$ values suggesting some statistical heterogeneity [23]. Possible reasons for this were that different magnetic field values (0.3$1.5 \mathrm{~T}$ ) were used in different studies and/or experiences of the MRI radiologist in different hospitals were different.

\section{Conclusions}

The available result suggests that MRI has better diagnostic accuracy for plantar plate tears than US. However, the concerns of risk for bias and heterogeneity should also be considered. High-quality trials are needed to assess the accuracy of MRI compared to US.

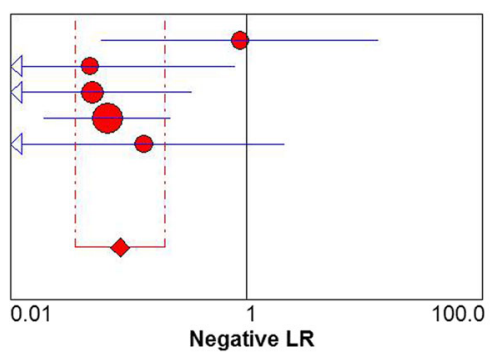

Gregg 2006 Klein 2012 Nery 2013

Sung 2012

Yao

Random Effects Model

Pooled Negative LR $=0.08(0.04$ to 0.20$)$

Cochran $-\mathrm{Q}=3.59 ; \mathrm{df}=4(\mathrm{p}=0.4644)$

inconsistency (I-square) $=0.0 \%$

Tau-squared $=0.0000$

Fig. 5 Forest plot depicting the negative likelihood ratio (NLR) for the use of MRI in the detection of plantar plate tears 


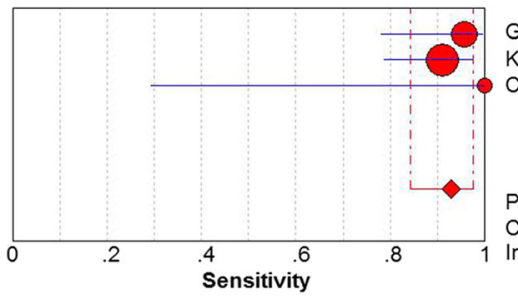

Gregg 2006

Klein 2013

Carlson 2012

Sensitivity $(95 \% \mathrm{Cl})$

$0.96 \quad(0.78-1.00)$

$0.91 \quad(0.79-0.98)$

$1.00(0.29-1.00)$

Pooled Sensitivity $=0.93(0.84$ to 0.98$)$

Chi-square $=0.95 ; \mathrm{df}=2(\mathrm{p}=0.6223)$

Inconsistency (I-square) $=0.0 \%$

Fig. 6 Forest plot depicting the sensitivity for the use of US in the detection of plantar plate tears

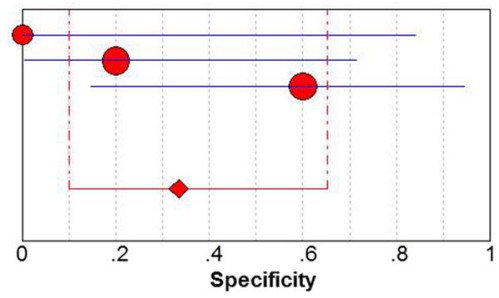

Gregg 2006

Klein 2013

Carlson 2012

Specificity $(95 \% \mathrm{Cl})$

$0.00 \quad(0.00-0.84)$

$0.20 \quad(0.01-0.72)$

$0.60 \quad(0.15-0.95)$

Pooled Specificity $=0.33(0.10$ to 0.65$)$

Chi-square $=3.54 ; \mathrm{df}=2(\mathrm{p}=0.1701)$

Inconsistency $($ I-square $)=43.5 \%$

Fig. 7 Forest plot depicting the specificity for the use of US in the detection of plantar plate tears

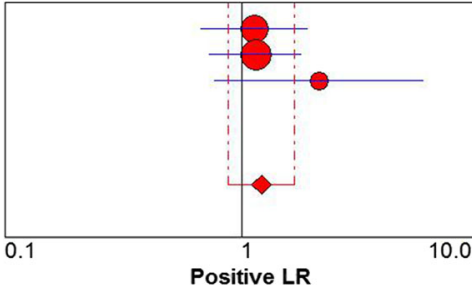

$\begin{array}{lll}\text { Gregg } & 1.13 & (0.67 \\ \text { Klein } & 1.14 & (0.73 \\ \text { Russel } & 2.10 & (0.76 \\ & \\ & \\ \text { Random Effects Model } \\ \text { Pooled Positive } L R=1.20(0.87 \text { to } 1.66) \\ \text { Cochran- } Q=1.40 ; \text { df }=2(p=0.4975) \\ \text { Inconsistency }(1-\text { square })=0.0 \% \\ \text { Tau-squared }=0.0000\end{array}$

Fig. 8 Forest plot depicting the positive likelihood ratio (PLR) for the use of US in the detection of plantar plate tears
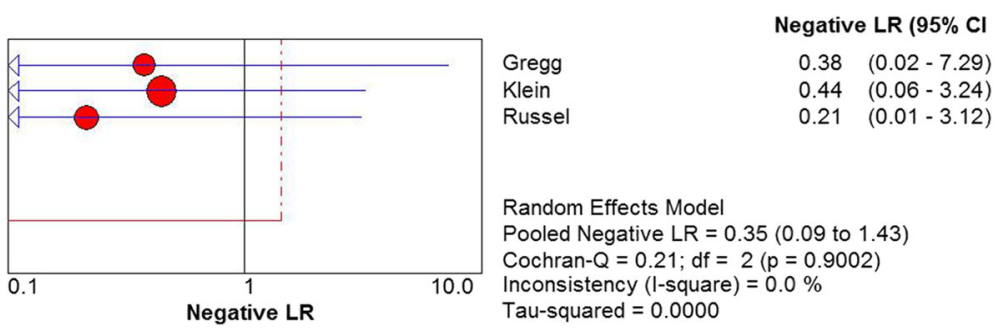

Russel

Random Effects Model

Pooled Negative LR $=0.35$ (0.09 to 1.43 )

Cochran- $Q=0.21 ; \mathrm{df}=2(\mathrm{p}=0.9002)$

Inconsistency (I-square) $=0.0 \%$

Tau-squared $=0.0000$

Fig. 9 Forest plot depicting the negative likelihood ratio (NLR) for the use of MRI in the detection of plantar plate tears 


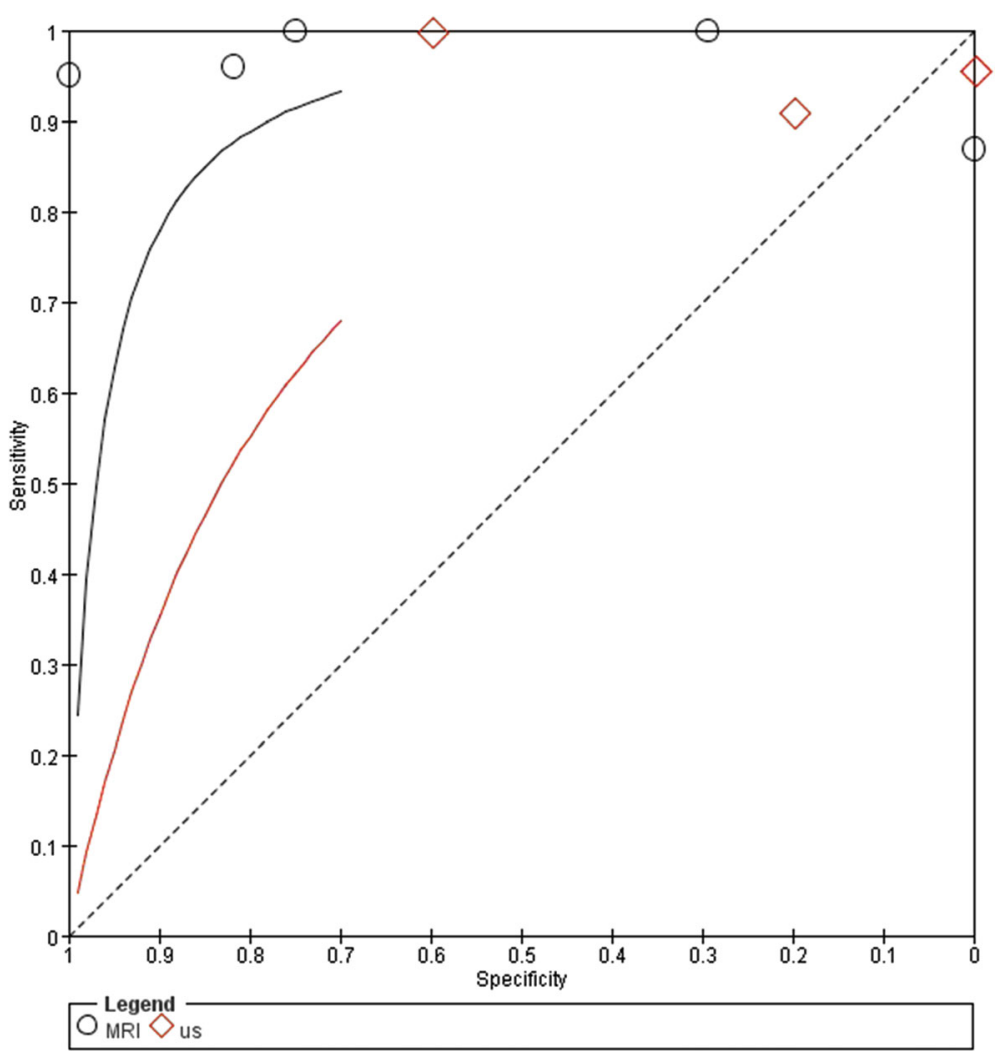

Fig. 10 Summary receiver operator characteristic (SROC) comparing the diagnostic accuracy of MRI to US in the detection of plantar plate tears

\section{Abbreviations}

DF: Degrees of freedom; MRI: Magnetic resonance imaging; US: Ultrasound

\section{Acknowledgements}

This work was supported by funding from the National Natural Science Foundation of China (no. 31370984 and 81501879) and Project of Sichuan Provincial Science and Technology Department (no. 2014HH0001 and 2015HH0049).

\section{Availability of data and materials}

Not applicable.

\section{Authors' contributions}

$X D$ and $L L$ was responsible for the drafting of the paper and conducting the manuscript. All authors read and approved this study.

\section{Competing interests}

The authors declare that they have no competing interests.

\section{Consent for publication}

No applicable.

\section{Ethics approval and consent to participate}

Not applicable.

\section{Author details}

'Orthopedics Department, West China Hospital, Sichuan University, \#37 Guoxuexiang Street, Chengdu 610017, Sichuan Province, China. ${ }^{2}$ Department of Bone and Joint Surgery, Affiliated Hospital of Westsouth Medical University, \#25 Taiping Steeet, Luzhou, Sichuan Province, China. ${ }^{3}$ Anesthesia Department, West China Hospital, Sichuan University, \# 37 Guoxuexiang Street, Chengdu, Sichuan province, China.
Received: 31 May 2016 Accepted: 22 December 2016

Published online: 21 January 2017

References

1. Deland JT, Lee KT, Sobel M, DiCarlo EF. Anatomy of the plantar plate and its attachments in the lesser metatarsal phalangeal joint. Foot Ankle Int. 1995; 16(8):480-6.

2. Umans HR, Elsinger $E$. The plantar plate of the lesser metatarsophalangeal joints: potential for injury and role of MR imaging. Magn Reson Imaging Clin N Am. 2001;9(3):659-69. xii.

3. Mohana-Borges AV, Theumann NH, Pfirrmann CW, Chung CB, Resnick DL, Trudell DJ. Lesser metatarsophalangeal joints: standard MR imaging, MR arthrography, and MR bursography_-initial results in 48 cadaveric joints. Radiology. 2003;227(1):175-82.

4. Bouche RT, Heit EJ. Combined plantar plate and hammertoe repair with flexor digitorum longus tendon transfer for chronic, severe sagittal plane instability of the lesser metatarsophalangeal joints: preliminary observations. J Foot Ankle Surg. 2008;47(2):125-37.

5. Ford LA, Collins KB, Christensen JC. Stabilization of the subluxed second metatarsophalangeal joint: flexor tendon transfer versus primary repair of the plantar plate. J Foot Ankle Surg. 1998;37(3):217-22.

6. Yu GV, Judge MS, Hudson JR, Seidelmann FE. Predislocation syndrome. Progressive subluxation/dislocation of the lesser metatarsophalangeal joint. J Am Podiatr Med Assoc. 2002:92(4):182-99.

7. Mendicino RW, Statler TK, Saltrick KR, Catanzariti AR. Predislocation syndrome: a review and retrospective analysis of eight patients. J Foot Ankle Surg. 2001; 40(4):214-24.

8. Kaz AJ, Coughlin MJ. Crossover second toe: demographics, etiology, and radiographic assessment. Foot Ankle Int. 2007;28(12):1223-37.

9. Oliver TB, Beggs I. Ultrasound in the assessment of metatarsalgia: a surgical and histological correlation. Clin Radiol. 1998;53(4):287-9.

10. Klein EE, Weil Jr L, Weil Sr LS, Knight J. Magnetic resonance imaging versus musculoskeletal ultrasound for identification and localization of plantar plate tears. Foot Ankle Spec. 2012;5(6):359-65. 
11. Gregg J, Silberstein M, Schneider T, Marks P. Sonographic and MRI evaluation of the plantar plate: a prospective study. Eur Radiol. 2006;16(12): 2661-9.

12. Moher D, Liberati A, Tetzlaff J, Altman DG, Group P. Preferred reporting items for systematic reviews and meta-analyses: the PRISMA statement. J Clin Epidemiol. 2009;62(10):1006-12.

13. Whiting P, Rutjes AW, Dinnes J, Reitsma J, Bossuyt PM, Kleijnen J. Development and validation of methods for assessing the quality of diagnostic accuracy studies. Health Technol Assess. 2004;8(25):iii. 1-234

14. Whiting PF, Weswood ME, Rutjes AW, Reitsma JB, Bossuyt PN, Kleijnen J. Evaluation of QUADAS, a tool for the quality assessment of diagnostic accuracy studies. BMC Med Res Methodol. 2006;6:9.

15. Reitsma JAR, Whiting P. Chapter 9: assessing methodological quality. In: Deeks JJ, Bossuyt PM, Gatsonis C, editors. Cochrane Handbook for Systematic Reviews of Diagnostic Test, The Cochrane Collaboration. 2009.

16. Carlson RM, Dux K, Stuck RM. Ultrasound imaging for diagnosis of plantar plate ruptures of the lesser metatarsophalangeal joints: a retrospective case series. J Foot Ankle Surg. 2013;52(6):786-8.

17. Klein EE, Weil Jr L, Weil Sr LS, Knight J. Musculoskeletal ultrasound for preoperative imaging of the plantar plate: a prospective analysis. Foot Ankle Spec. 2013;6(3):196-200.

18. Nery C, Coughlin MJ, Baumfeld D, Mann TS, Yamada AF, Fernandes EA. MRI evaluation of the MTP plantar plates compared with arthroscopic findings: a prospective study. Foot Ankle Int. 2013;34(3):315-22.

19. Sung W, Weil Jr L, Weil Sr LS, Rolfes RJ. Diagnosis of plantar plate injury by magnetic resonance imaging with reference to intraoperative findings. J Foot Ankle Surg. 2012;51(5):570-4.

20. Yao L, Cracchiolo A, Farahani K, Seeger LL. Magnetic resonance imaging of plantar plate rupture. Foot Ankle Int. 1996;17(1):33-6.

21. Yao L, Do HM, Cracchiolo A, Farahani K. Plantar plate of the foot: findings on conventional arthrography and MR imaging. AJR Am J Roentgenol. 1994;163(3):641-4.

22. Fernandes Ede A, Mann TS, Puchnick A, Tertulino Fde F, Cannato CT, Nery C, Fernandes Ada R. Can ultrasound of plantar plate have normal appearance with a positive drawer test? Eur J Radiol. 2015;84(3):443-9.

23. Deeks JJ, Higgins JP, Altman DG. Analysing Data and Undertaking Meta-Analyses. In: Higgins JP, Green S, editors. Cochrane Handbook for Systematic Reviews of Interventions: Cochrane Book Series. Chichester: Wiley; 2008. doi:10.1002/9780470712184.ch9.

\section{Submit your next manuscript to BioMed Central and we will help you at every step:}

- We accept pre-submission inquiries

- Our selector tool helps you to find the most relevant journal

- We provide round the clock customer support

- Convenient online submission

- Thorough peer review

- Inclusion in PubMed and all major indexing services

- Maximum visibility for your research

Submit your manuscript at www.biomedcentral.com/submit

) Biomed Central 